\title{
Performance and Emission Analysis of a Diesel Engine Using Linseed Biodiesel Blends
}

\author{
M. M. Tunio \\ Department of Energy and \\ Environment Engineering \\ Quaid-e-Awam University of \\ Engineering, Science and \\ Technology \\ Nawabshah, Pakistan \\ mureed.tunio@gmail.com
}

\author{
M. R. Luhur \\ Department of Mechanical \\ Engineering \\ Quaid-e-Awam University of \\ Engineering, Science and \\ Technology \\ Nawabshah, Pakistan \\ luhur@quest.edu.pk
}

\author{
Z. M. Ali \\ Department of Chemical \\ Engineering \\ Mehran University of \\ Engineering and Technology \\ Jamshoro, Pakistan \\ zeenat.ali@faculty.muet.edu.pk
}

\author{
U. Daher \\ Department of Chemistry \\ Govt. Degree (Boys) College \\ Sakrand, Pakistan \\ oooga82@gmail.com
}

\begin{abstract}
The core object of this study is to examine the suitability of linseeds for biodiesel production. The performance of an engine at different proportions of linseed blends with petrodiesel and the amount of emissions rate were investigated. Initially, linseed biodiesel was produced through transesterification process, and then it was mixed with petrodiesel fuel (D100) blends at volumetric ratios of $10 \%$ (LB10), $20 \%$ (LB20), and 30\% (LB30). The properties of linseed biodiesel and its blends were investigated and compared with petro-diesel properties with reference to ASTM standards. It has been observed that the fuel properties of produced biodiesel are within ASTM permissible limits. The specific fuel consumption (SFC) of LB10 blend has been found lesser compared to LB20 and LB30. SFC of D100 is slightly less than that of all the blends. The brake thermal efficiency (BTE) of LB30 is greater than that of pure diesel D100 at maximum load and greater than that of LB10 and LB20. The heat dissipation rate in all linseed blends is found to have been less than that of D100. Carbon monoxide, carbon dioxide and NOx emissions of linseed blends are mostly lower in comparison with D100's. Among all blends, LB10 was found more suitable alternative fuel for diesel engines and can be blended with petro diesel without engine modifications. It can be concluded that cultivation and production of linseed in Pakistan is very promising, therefore, it is recommended that proper exploitation and use of linseed for energy production may be encouraged through pertinent agencies of Pakistan.
\end{abstract}

Keywords-linseed oil; transesterification; diesel-biodiesel blends; engine performance; emission analysis

\section{INTRODUCTION}

The demand of energy sources is increasing day by day due to population growth, urbanization and industrialization. Fossil fuels are conventional energy sources and are used for power production for a long time. However, they are finite sources of energy and cannot be replenished once consumed. Environmental consequences are also major drawbacks of fossil fuel consumption. Therefore, it is an inevitable to explore alternative energy sources which must be environmental friendly to fulfill growing energy demand [1]. Out of all agricultural sources, linseed is preferable because of its reasonable availability and easy accessibility, especially in
Sindh and Punjab Pakistan provinces [2]. Pakistan is an energy deficient country, as demand is larger than production capacity. Energy shortage and frequent load shedding have created a chaotic situation in every corner of the country [3]. The Government of Pakistan is encouraging and promoting research and efforts to utilize renewable energy sources to supplement fossil fuels. Pakistan has a good potential of edible and nonedible crops for biodiesel (bio-energy) production. Among all non-edible feed stocks, linseed is recognized to be one of the most suitable sources for biodiesel production as it is an oil seed bearing plant [4]. Linseed oil is a non-edible vegetable oil and is considered as a potential alternative fuel for the compression ignition engines. It is a sulfur free, non-aromatic, nontoxic, and oxygenated oil. Moreover, Pakistani Government is eager to introduce blended petroleum (with biodiesel) at a national level in order to meet the increasing energy demand. It was decided that $5 \%$ by volume of diesel will be blended with biodiesel up to 2015 and gradually the analogy will increase up to $10 \%$ in 2025 [5]. However, this has not been achieved yet due to the delay in large scale biodiesel production level, less foreign investment and lack of infrastructure facilities.

Linseed (Linum Usitatissimum L.) locally known as "alsi" is an annual winter plant grown for fiber and oil. It is a herbaceous annual-type plant that is cultivated in 59 countries for its fiber as well as its oil [6]. Linseed contains oil at 35-45\% by weight and is high in unsaturated constitutes [7]. In Pakistan, linseed is cultivated on marginal and sub-marginal lands under irrigated conditions. Linseed is cultivated in Punjab and Sindh provinces in 762 and 2929 hectares of land respectively, and its whole country cultivation was around 3691 hectares during 2014-15. The quantity of linseed production was 2622 tons during 2014. Its yield in $\mathrm{kg}$ per hectare was 758 in Sindh and 697in Punjab, while its national average yield during $2014-15$ was $710 \mathrm{~kg} / \mathrm{ha}$ [8]. Various chemical properties and characteristics of linseed seeds, extracted oil and biodiesel produced decide its suitability for the replacement of petro diesel in internal combustion engines and other industrial applications.

This study aimed to produce linseed biodiesel using indigenous linseed seeds and to examine the performance of a 
diesel engine by using its different blends with petro diesel and exhaust emission rates. The study includes physcio-chemical properties of produced biodiesel, such as density, flash point, kinematic viscosity, cetane number, pour point, and calorific value. The performance parameters, like brake thermal efficiency (BTE), fuel consumption, and heat carried by coolant were evaluated at varying loads. Regarding exhaust gas emission, Nitrogen dioxide $\left(\mathrm{NO}_{2}\right)$, Nitrogen oxides (NOx), Carbon monoxide (CO), carbon dioxide (CO2), PM2.5 \& PM10 were also analyzed. The emission of particulate matter is known as a major contributor to global warming as well as a critical air pollutant [9]. The objective of this study was to draw attention to the synthesis of linseed biodiesel, which is an excellent alternate of petroleum diesel, especially in Pakistan.

\section{MATERIALS AND METHODS}

The experimental work produced biodiesel using refined linseed oil as raw material. It also investigated the performance and emission characteristics of linseed methyl ester using different blends and compared them with petro diesel. The linseeds were purchased from the local markets of Hyderabad, Sindh, Pakistan. The linseed oil can be obtained by different methods like solvent extraction, enzymatic extraction and screw press method. The screw press method is preferable as it gives more yields and so it was adopted $[10,11]$. The crude linseed oil was extracted with the help of the screw press mechanical expeller of the Biofuel Laboratory, Department of Energy and Environment Engineering, QUEST, Nawabshah. At first, the linseed seeds were cleaned in order to avoid the impurities, foreign particles and adhered agrochemical sprays remaining on the outer seed's surface. The extracted oil was collected in air sealed glass bottles which were already sterilized, washed with double distilled water and oven dried. Oil's free fatty acid level was reduced through single esterification.

\section{A. Transesterification Process}

Linseed biodiesel was produced through transesterification. It was produced using a five hole lid reactor which was equipped with mechanical stirrer, temperature controller, thermometer with cork reflux condenser. Various experiments were made at different molar ratio to obtained maximum biodiesel yield. The mixture was agitated with the help of the mechanical stirrer by keeping its speed at $600 \mathrm{rpm}$ under $55^{\circ} \mathrm{C}$ for 30 minutes. At the end of the transesterification, the crude methyl ester was transferred into a separating funnel for 24 hours. The crude methyl ester was washed with water and then dried to remove its moisture content and unwanted reagents.

\section{B. Blend Preparaton, Engine Performance and Exhaust Emissions}

The blends of varying ratio of linseed biodiesel and petrodiesel were prepared at room temperature in Biofuel Laboratory. The linseed biodiesel was blended with petro diesel at volumetric ratios of 10\% (LB10), 20\% (LB20) and $30 \%$ (LB30) as shown in Figure 1. The different blends of linseed biodiesel were tested on a slow speed diesel engine, (Model DWE-6/10-JS-DV). The specifications are mentioned in Table I [12].

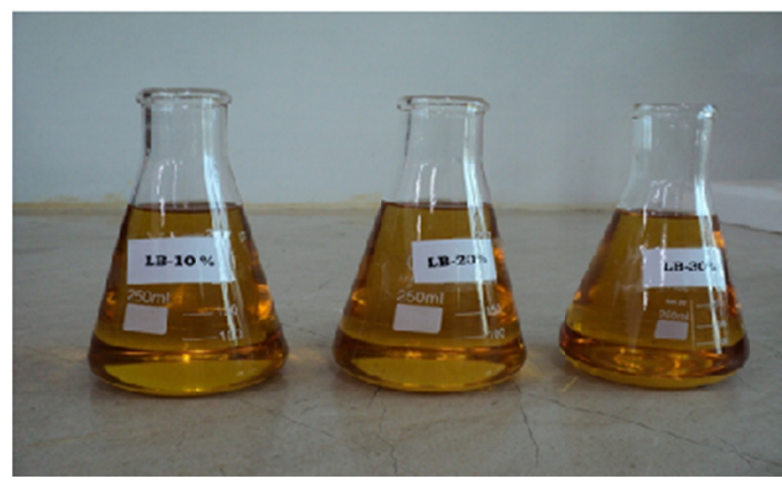

Fig. 1. Linseed biodiesel blends

TABLE I. DIESEL ENGINE SPECIFICATIONS [12]

\begin{tabular}{|c|c|}
\hline Parameter & Specification \\
\hline Type & Horizontal \\
\hline Model & DWE-6/10-JS-DV \\
\hline Number of cylinder & $80 \mathrm{~mm}$ \\
\hline Bore & $95 \mathrm{~mm}$ \\
\hline Stroke & $23: 01$ \\
\hline Compression ratio & Manual \\
\hline Starting method & $8.5 \mathrm{PS}$ \\
\hline Output & $3 \mathrm{kw}$ \\
\hline Maxium load & $2200 \mathrm{rpm}$ \\
\hline Rotational Speed & Water cooled \\
\hline Cooling type & Float type \\
\hline Dynamometer & Eddy current electro brake \\
\hline Flow meter &
\end{tabular}

The engine comprises of several systems such as lubricating system, fuel supply system, water cooling system and several sensors which are attached with measuring devices in an integrated manner [12]. The load on the engine was increased gradually (step: $0.75 \mathrm{~kW}$ ) from zero to the maximum of $3 \mathrm{~kW}$. The increase of load on the engine decreases the rpm of the engine from 2200 to 1200 . The power output (torque) was measured by an eddy current electric dynamometer. Fuel consumption was measured on volumetric basis [12, 13]. Performance parameters like speed, torque, brake specific fuel consumption (BSFC), lubrication oil temperature, water inlet and outlet temperatures, suction and exhaust pressures, exhaust temperature and thermal efficiency were examined. Moreover, Gas analyzer $350 \mathrm{XL}$ testo-meters were used for the analysis of various flue gas emissions like carbon monoxide (CO), carbon dioxide (CO2), and nitrogen oxides $\left(\mathrm{NO}_{\mathrm{X}}\right)$ [14]. PM2.5 and PM10 were determined by Particulate Meter Aerocet Model No. 531S.

\section{RESULTS AND DISCUSSION}

\section{A. Fuel Properties and Engine Performance}

The results of the properties of the different blends of produced linseed biodiesel are shown in Table II. The produced biodiesel was found to have lower viscosity and density, higher cetane number and flash point. In blend LB10, maximum cetane number was found to be 53.5, whereas, in LB20 it was 52.5 , which is more than the ASTM Standard. Flash point was discovered to be more in LB20 and LB30 than petro diesel. Sulfur was found less in all blends than that in $100 \%$ diesel. 
The calorific values were within permissible limits. Generally, all fuel properties of LB10 blend were found better in term of less kinematic viscosity, higher cetane number, even elevated calorific values. B10 was found to be more suitable feasible blend compared to LB20 and LB30. All blend samples were found better than petro diesel. The results were found similar to the ones reported in [15-16]. Engine performance or brake power output was examined by load variation. The variation in specific fuel consumption (SFC) versus brake power for different fuel blends is shown in Figure 2. In general, at $0.75 \mathrm{~kW}$ power, SFC was found maximum, and it decreased with the increase of brake power. However, SFC in LB10 blend found less as compared to LB20 and LB30. At the maximum brake power D100 performed well with respect to specific fuel consumption (SFC).

TABLE II. FUEL PROPERTIES OF LINSEED BIODIESEL AND BLENDS

\begin{tabular}{|c|c|c|c|c|c|c|}
\hline Quality Parameters & Allowable limits & Diesel $100 \%$ & LB $100 \%$ & LB $10 \%$ & LB $20 \%$ & LB 30\% \\
\hline Density at $15^{\circ} \mathrm{C} \mathrm{kg} / \mathrm{Lit}$ & 0.88 & 0.8401 & 0.8809 & 0.8945 & 0.8509 & 0.8561 \\
\hline Kinematic Viscosity at $40^{\circ} \mathrm{C}\left(\mathrm{mm}^{2} / \mathrm{SEC}\right)$ & $1.9-6.0$ & 3.06 & 4.17 & 3.57 & 3.67 & 3.81 \\
\hline Sulfur \%wt & $0.05 \max$ & 0.735 & 0.0093 & 0.125 & 0.113 & 0.1007 \\
\hline Flash point ${ }^{\circ} \mathrm{C}$ & $130 \mathrm{~min}$ & 74 & 172 & 74 & 78 & 81 \\
\hline Total Acid Number mgKOH/gm & $0.80 \max$ & 0.249 & 1.22 & 1.48 & 1.59 & 1.64 \\
\hline Pour point ${ }^{\circ} \mathrm{C}$ & -15 to +5 & 0 & -3 & -9 & -9 & -6 \\
\hline Cetane number & $47 \mathrm{mini}$ & 52 & 45 & 53.5 & 52.5 & 50.5 \\
\hline Calorific value $\mathrm{MJ} / \mathrm{kg}$ & $37.5-42.80$ & 44.2 & 42.85 & 41.8 & 41.5 & 40.8 \\
\hline
\end{tabular}

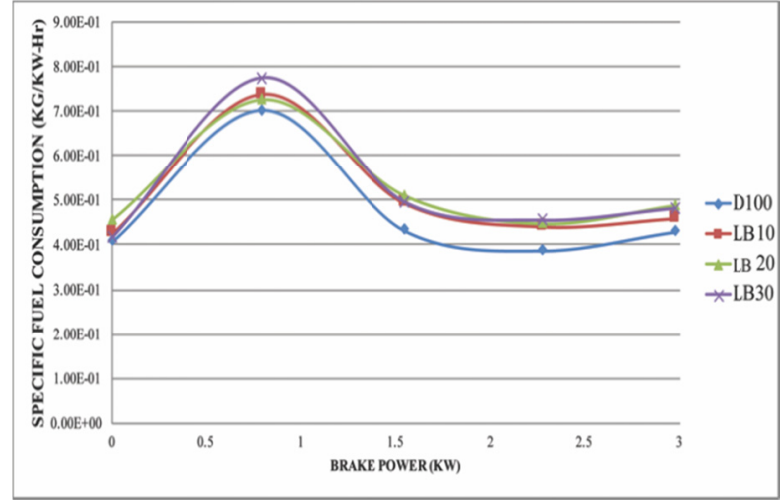

Fig. 2. Brake power versus brake specific fuel consumption

Figure 3 shows the deviation of BTE versus brake power output for the different blends of linseed biodiesel. BTE was found to increase with increase of brake power. BTE of LB30 was found greater than that of pure diesel D100, LB10 and LB20 at maximum load. LB30 blend could be practically applied in Internal Combustion (IC) engine due to its higher thermal efficiency. Figure 4 shows the variation of heat carried out by coolant (HC) versus brake power for the different blends. The heat dissipation rate was found less in all linseed blends than that of D100. At zero load LB10 recorded less than LB20 and LB30, whereas at full load LB30 had less than LB20 and LB10. This reveals that the engine can run smoothly without heating resultantly with the use of linseed biodiesel blends. Lubrication oil consumption could be less, therefore, it would be economical for the operation of IC engines.

\section{B. Exhaust Emissions}

Table III shows the exhaust emissions such as $\mathrm{CO}, \mathrm{CO}_{2}$ and $\mathrm{NOx} \mathrm{NO}, \mathrm{NO}_{2}, \mathrm{PM} 2.5$ and PM10 by load. In this study exhaust emissions of biodiesel blends were compared with diesel's. Among vehicular fuels, petro-diesel produces slightly larger quantities of particulate matters, which consists of carbonaceous material [17]. As a result, by the use of alternate biofuels the environmental impacts can be reduced. By using diesel the PM2.5 were recorded $0.09 \mathrm{mg} / \mathrm{m}^{3}$, whereas $\mathrm{LB} 10$, LB20 and Lb30 emissions were $0.002,0.040$ and $0.010 \mathrm{mg} / \mathrm{m}^{3}$ respectively. Similarly, PM10 was observed $2.157 \mathrm{mg} / \mathrm{m}^{3}$, while in LB10, LB20 and Lb30 were 1.356, 1.308 and $0.732 \mathrm{mg} / \mathrm{m}^{3}$ respectively. Generally biodiesel's PM emission is lesser than diesel's. The PM formation process mainly occurs in fuel-rich zones and high temperatures. Since biodiesel contains more oxygen than diesel, thereby PM emission is decreased [18].

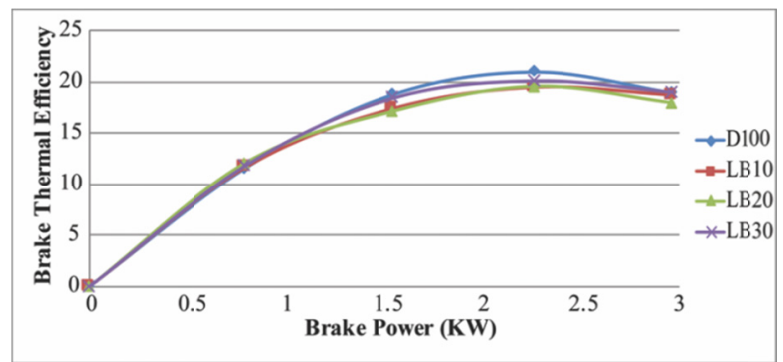

Fig. 3. Brake power versus brake thermal efficiency for the test fuels

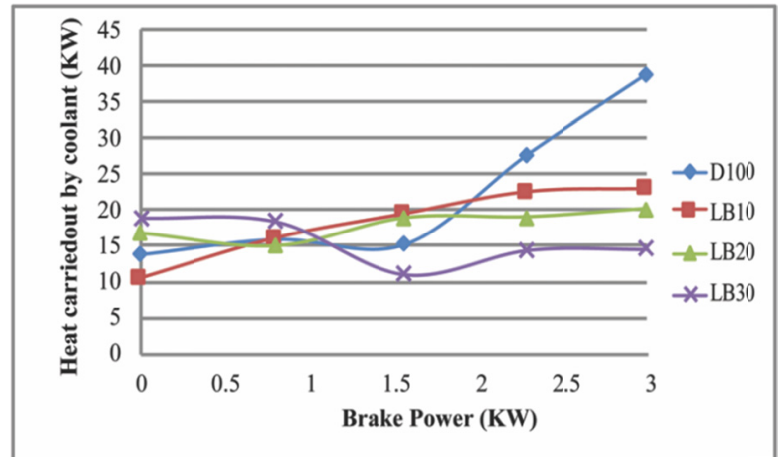

Fig. 4. Brake power versus heat carried out by coolant for the test fuels

$\mathrm{CO}$ is a formation mixture of temperature and unburned flue gases, which when put together control the rate of fuel 
decomposition and oxidation [19]. All biodiesel blends provide lesser CO emissions compared to petro diesel. LB10 blend gave slightly lower emission than LB20 and LB30. Similar results were also reported in [19-20]. The percentage of carbon dioxide $\left(\mathrm{CO}_{2}\right)$ emission was found increasing with the increase of biodiesel ratios at full load condition but remained lower than that of petro diesel.

The nitrogen oxide levels $\left(\mathrm{NO}_{\mathrm{x}}\right)$ is an exhaust emission of diesel engines. It could create health hazards, when it is inhaled. It can cause many diseases, like tuberculosis, severe headache, respiratory problems, lung cancer, nausea, skin cancer etc. [21]. The $\mathrm{NO}_{\mathrm{x}}$ emissions of all blends were found lower than that of petro diesel. Among all blends, LB20 blend emission was much lower than the ones of LB10 and LB30. This reveals that the linseed biodiesel is feasible using blend forms for $\mathrm{NO}_{\mathrm{x}}$ reduction. Similarly, other pollutant results, like $\mathrm{NO}_{2}, \mathrm{NO}$ and $\mathrm{CO}_{2}$ remained lower than that of $100 \%$ diesel.

TABLE III. COMPARISON OF EXHAUST EMISSIONS

\begin{tabular}{|c|c|c|c|c|c|c|c|c|c|c|c|c|c|c|c|c|}
\hline Parameters & \multicolumn{4}{|c|}{ Diesel } & \multicolumn{4}{|c|}{ LB10 } & \multicolumn{4}{|c|}{ LB20 } & \multicolumn{4}{|c|}{ LB30 } \\
\hline Engine load (\%) & 25 & 50 & 75 & 100 & 25 & 50 & 75 & 100 & 25 & 50 & 75 & 100 & 25 & 50 & 75 & 100 \\
\hline PM2.5 (mg/m3) & 0.14 & 0.16 & 0.66 & 0.60 & 0.02 & 0.04 & 0.012 & 0.002 & 0.02 & 0.03 & 0.005 & 0.04 & 0.005 & 0.029 & 0.056 & 0.010 \\
\hline PM10 (mg/m3) & 0.87 & 0.84 & 1.52 & 2.15 & 0.52 & 0.73 & 0.31 & 1.35 & 0.42 & 0.58 & 0.74 & 1.30 & 0.36 & 0.39 & 0.42 & 0.73 \\
\hline $\mathrm{NO}_{2}(\mathrm{ppm})$ & 9.30 & 8.10 & 8.88 & 8.98 & 8.50 & 3.10 & 1.20 & 0.05 & 6.70 & 1.50 & 0.70 & 0.40 & 1.80 & 3.90 & 0.20 & 0.15 \\
\hline $\mathrm{NO}_{\mathrm{x}}(\mathrm{ppm})$ & 98.0 & 79.0 & 37.0 & 77.0 & 48.0 & 59.0 & 65.0 & 30.0 & 57 & 66.0 & 63.0 & 11.0 & 46.0 & 88.0 & 45.0 & 15.0 \\
\hline $\mathrm{CO}(\mathrm{ppm})$ & 425 & 480 & 510 & 530 & 182 & 188 & 269 & 365 & 161 & 200 & 201 & 328 & 210 & 235 & 264 & 372 \\
\hline $\mathrm{NO}_{2}(\mathrm{ppm})$ & 65.0 & 73.0 & 70.0 & 68.0 & 40.0 & 55.0 & 64.0 & 29.0 & 51.0 & 65.0 & 63.0 & 60.0 & 45.0 & 55.0 & 65.0 & 60.0 \\
\hline $\mathrm{CO}_{2} \%(\mathrm{ppm})$ & 4.2 & 3.4 & 3.5 & 4.82 & 1.69 & 2.17 & 2.65 & 2.93 & 1.70 & 2.34 & 2.73 & 3.44 & 1.59 & 2.36 & 3.00 & 3.68 \\
\hline
\end{tabular}

\section{CONCLUSIONS}

Linseed biodiesel was produced through transesterification process using indigenous linseeds. The produced biodiesel was blended with petro-diesel fuel (D100) at different volumetric ratios of $10 \%$ (LB10), 20\% (LB20), and 30\% (LB30). The fuel properties of produced biodiesel were found within ASTM permissible limits. The specific fuel consumption of LB10 blend was found less than that of LB20, and LB30. BTE of LB30 is greater than pure diesel's D100 at the maximum load. The heat dissipation rate was found less in all blends of linseed than that of D100. This reveals that the diesel engines can run smoothly without heating with the use of linseed blends. Both particulate matters PM2.5 and PM10 results were investigated and it was found that PM emission is drastically less than petro-diesel's at all loads. The $\mathrm{CO}_{2}$ and $\mathrm{NO}_{\mathrm{x}}$ emissions of linseed blends were found lower when compared to petro diesel fuel. Among all blends, LB10 was found to be more suitable alternative fuel for diesel engines and can be blended with petro diesel without engine modifications. It was also observed that cultivation and production of linseed in Pakistan is very promising therefore it is recommended that the proper exploitation and use of linseed for energy production may be encouraged by the relevant agencies of Pakistan.

\section{REFERENCES}

[1] S. Kumar, A. Pal, A. Baghel, "An Experimental Analysis of Biodiesel Production from Linseed Oil", International Journal of Engineering Technology, Management and Applied Sciences, Vol. 3, No. 2, pp. 133140,2015

[2] S. Ali, M. A. Cheema, M. A. Wahid, A. Sattar, M. F. Saleem, "Comparative production potential of linola and linseed under different nitrogen levels", Crop \& Environment, Vol. 2, pp. 33-36, 2011

[3] M. Asif, "Sustainable energy options for Pakistan", Renewable and Sustainable Energy Reviews, Vol. 13, No. 4, pp. 903-909, 2009

[4] S. A. R. Kazmi, A. H. Solangi, S. N. A. Zaidi, Jatropha curcas L. Cultivation Experience in Karachi Pakistan, Joint Study Preliminary Report of Pakistan Agricultural Research Council and Pakistan State Oil, 2003
[5] A. B. Awan, Z. A. Khan, "Recent progress in renewable energy-remedy of energy crisis in Pakistan", Renewable and Sustainable Energy Reviews, Vol.33, pp. 236-253, 2014

[6] Food and Agriculture Organization of the United Nations, Food and Agriculture Organization Corporate Statistical Database, available at: http://www.fao.org/faostat/en/\#home, Accessed: 03/02/2018.

[7] F. Ullah, A. Bano, S. Ali, “Optimization of protocol for biodiesel production of linseed (Linum usitatissimum L.)oil”, Polish Journal of Chemical Technology, Vol. 15, No. 1, pp. 74-7, 2013

[8] M. Amjad, Oilseed crops of Pakistan Pakistan Agricultural Research Council, Islamabad, 2014

[9] C.-J. Ruan,W.-H. Xing, J. A. T. da Silva, "Potential of five plants growing on unproductive agricultural lands as biodiesel resources", Renewable Energy, Vol. 41, pp. 191-199, 2012

[10] P. Beerens, Screw-pressing of Jatropha seeds for fuelling purposes in less developed countries", MSc Thesis, Eindhoven University of Technology, Ministerio de Ambiente y Energía, 2007

[11] M. M. Tunio, S. R. Samo, Z. M. Ali, K. Chand, "Comprehensive study of Jatropha (Jatropha curcas) Biodiesel production and its prospectus in Pakistan”, Sindh University Research Journal (Science Series), Vol. 48, No. 1, pp. 209-212, 2016

[12] Tokyo Meter Co, Operational Manual of Single cylinder slow speed diesel engine research and test bed, Model: Dwe-6/10-Js -DV, 2002

[13] K. Singh, M. Y. Sheikh, Y. B. Mathur, "Performance study of a VCR diesel engine fueled with diesel and low concentration blend of linseed oil biodiesel", International Journal of Emerging Technology and Advanced Engineering, Vol. 4, No. 4, pp. 295-299, 2014

[14] Testo, Testo $350 \mathrm{M} / \mathrm{XL} 454$ Instruction Manual, 2002

[15] S. R. Samo, M. M. Tunio, "Production and Characterization of Biodiesel from Indigenous Linseed Herb", International Journal of Current Trends in Engineering \& Research" Vol. 2, No. 8, pp. 91-97, 2016

[16] A. M. Ashraful, H. H. Masjuki, M. A. Kalam, I. R. Fattah, S. Imtenan, S A. Shahir, H. M. Mobarak, "Production and comparison of fuel properties, engine performance, and emission characteristics of biodiesel from various non-edible vegetable oils: a review", Energy Conversion and Management, Vol. 80, pp. 202-228, 2014

[17] R. Sattanathan, "Production of Biodiesel from Castor oil with its Performance and Emission test", International Journal of Science and Reseach,Vol. 4, No. 1, pp. 273-279, 2015

[18] M. H. Shojaeefard, M. M. Etgahni, F. Meisami, A. Barari, "Experimental investigation on performance and exhaust emissions of castor oil biodiesel from a diesel engine", Environmental Technology, Vol. 34, No. 13-14, pp. 2019-2026, 2013 
[19] S. K. Mahla, A. Birdi, "Performance and Emission Characteristics of Different Blends of Linseed Methyl Ester on Diesel Engine", International Journal on Emerging Technologies, Vol. 3, No. 1, pp. 5559,2012

[20] M. Ozcanli, H. Serin, O. Y. Saribiyik, K. Aydin, S. Serin, "Performance and emission studies of castor bean (Ricinus Communis) oil biodiesel and its blends with diesel fuel", Energy Sources, Part A: Recovery, Utilization, and Environmental Effects, Vol. 34, No. 19, pp. 1808-1814, 2012

[21] M. M. Krishna, K. V. Krishna, "Experimental Investigations of comparative performance and exhaust emissions of linseed biodiesel fuelled DI diesel engine with low grade LHR combustion chamber", International Journal of Advanced Scientific and Technical Research, Vol. 5, No. 4, pp. 180-197, 2014 